\title{
MAL RADICAL E PSICOLOGIA MORAL EM KANT SEGUNDO JOHN RAWLS
}

\author{
RADICAL EVIL AND MORAL PSYCHOLOGY BY KANT ACCORDING TO JOHN \\ RAWLS
}

\author{
AGUINALDO PAVÃO \\ (Universidade Estadual de Londrina / Brasil)
}

\begin{abstract}
RESUMO
Em suas Lectures on the History of Moral Philosophy, Rawls esposa a interpretação de que Kant teria se comprometido, sobretudo na Fundamentação, com o que ele chama, tendo Agostinho como inspiração, de "psicologia moral maniqueísta". Esse flerte inicial acabaria, porém, sendo abandonado, na Religião, em favor de uma "psicologia moral agostiniana". Essa psicologia atribui exclusivamente à liberdade do arbítrio a fonte do mal moral e repele a ideia de que o mal teria como causa nossa natureza desiderativa ou, até mesmo, social. Pode-se afirmar que, ao fazer uso da expressão "psicologia moral agostiniana", Rawls apenas chama a atenção, com outro nome, para o que, mais consagradamente, tem sido chamado, a partir de Allison, de tese da incorporação. Esse parece um ponto incontroverso, ou majoritariamente aceito pelos comentaristas de Kant. Não me parece ser o caso, porém, da presença na filosofia moral de Kant do que Rawls chama de psicologia moral maniqueísta. Tal psicologia afirma a existência de dois eus, um bom, que temos à medida que pertencemos ao mundo inteligível, e outro mau, que possuímos como seres do mundo sensível. Rawls corretamente assinala as dificuldades que, de imediato, emergem a partir da psicologia moral maniqueísta, nomeadamente a relacionada à teoria do mal moral em geral e, correspondentemente, à compreensão da responsabilidade moral. O objetivo do artigo será discutir se Rawls tem razão em atribuir ao pensamento moral de Kant na Fundamentação essa tal psicologia moral maniqueísta. Defenderei que a leitura de Rawls, em seus aspectos mais gerais, é procedente. Sustentarei, porém, que certas considerações que Rawls faz sobre o mundo inteligível e o mundo sensível, especialmente sobre sua possível inoperância, ou abandono dessa distinção na Religião, não merecem acolhimento pleno. Também advogarei que a leitura de Rawls se ressente da ausência de um apelo a recursos conceituais internos à Fundamentação autenticadores da presença, nessa obra, da psicologia moral agostiniana.
\end{abstract}

Palavras-chave: psicologia moral, imputação, liberdade, bem, mal, livre arbítrio

\begin{abstract}
In his Lectures on the History of Moral Philosophy, Rawls defends the interpretation that Kant would be compromised, especially in the Groundwork, with "Manichean moral psychology". However, his initial approach would be abandoned, in Religion, in favor of an "Augustinian moral psychology." This psychology assigns exclusively to the freedom of choice the source of moral evil and rejects the idea that evil would has as cause our desiderative or even social nature. It can be argued that, by making use of the phrase "Augustinian moral psychology," Rawls only draws attention with another name the more well-known, "Incorporation Thesis" (so called from Henry Allison). This seems uncontroversial point, or overwhelmingly accepted by commentators on Kant. However, it does not seem to be the case with reference to the presence in Kant's moral philosophy of what Rawls calls Manichean moral psychology. Such psychology asserts the existence of two selves, a good, that we have while we belong to the intelligible world, and the other bad, that we have while we belong to the sensible world. Rawls rightly points out the difficulties that immediately emerge from the Manichean moral psychology, namely related to the theory of moral evil in general and, correspondingly, to the understanding of moral responsibility. The aim of the article will be to discuss if Rawls is right to attribute to Kant's moral thought in Groundwork such Manichean moral psychology. I will argue that the reading of Rawls, in its most general aspects, is well founded. Nevertheless, I will
\end{abstract}

ethic@-Florianópolis v.12,n.1, p.101-111, Jun. 2013. 
argue that certain considerations that Rawls makes about the intelligible world and sensible world, especially about its possible ineffectiveness, or abandonment of this distinction in Religion, cannot be accepted fully. I will defend also that Rawls's reading resents the absence of an appeal to internal conceptual resources presents in Groundwork. This presence can authenticate the Augustinian moral psychology.

Keywords: moral psychology, imputation, freedom, good, evil, choice

\section{Introdução}

Em suas Lectures on the History of Moral Philosophy, Rawls esposa a interpretação de que Kant teria se comprometido, sobretudo na Fundamentação da Metafísica dos Costumes, com o que ele chama, tendo Agostinho como inspiração, de "psicologia moral maniqueísta". Esse flerte inicial acabaria, porém, sendo abandonado, na Religião, em favor de uma "psicologia moral agostiniana”. Segundo Rawls, a teoria do mal radical apresentada na Religião vincula-se ao que se pode denominar de "psicologia moral agostiniana", uma vez que a característica distintiva de tal psicologia consistiria em atribuir exclusivamente à liberdade do arbítrio a fonte do mal moral. Essa psicologia repeliria a ideia de que o mal teria como causa nossa natureza desiderativa ou, até mesmo, social (cf. 2000: 294/ 2005: 337).

Com respeito à psicologia moral maniqueísta, Rawls acredita que sua "ideia básica [...] consiste em que temos dois eus: um deles é o eu bom, que temos enquanto inteligências pertencentes ao mundo inteligível; o outro é o eu mau, que temos enquanto seres naturais pertencentes ao mundo sensível” (2000:303/ 2005: 348). Rawls corretamente assinala as dificuldades que, de imediato, emergem a partir da psicologia moral maniqueísta, nomeadamente a relacionada à teoria do mal moral em geral e, correspondentemente, à compreensão da responsabilidade moral.

A leitura de Rawls, acima resumida, me parece em seus aspectos mais gerais, procedente. É claro que o tema do comprometimento dos juízos de responsabilidade moral tendo em vista uma possível identificação entre ação livre e ação moral não é um ponto original na interpretação que Rawls faz da filosofia moral de Kant. Dentre vários comentaristas que já apontavam para essa dificuldade, pode-se citar: Ferdinand Alquie (s/d: 96), Ralph Walker (1982: 147, 1989: 16 e 1999: 44), Hud Hudson (1991: 179-176) e Emil Fackenheim (1992). Divirjo, porém, de certas considerações que Rawls faz sobre o mundo inteligível e o mundo sensível, especialmente sobre sua possível inoperância, ou abandono dessa distinção na Religião. Também penso que a leitura de Rawls se ressente da ausência de um apelo a recursos conceituais internos à Fundamentação 
da metafísica dos costumes autenticadores da presença, nessa obra, da psicologia moral agostiniana. Porém, como se verá, concordo mais do que discordo da leitura de Rawls acerca da relação entre o mal radical e imputação moral em Kant.

\title{
2. Psicologia moral agostiniana, graus da maldade e tese da incorporação
}

Pode-se afirmar que, ao fazer uso da expressão "psicologia moral agostiniana", Rawls apenas chama a atenção, com outro nome, para o que mais consagradamente tem sido chamado, a partir de Allison, de "tese da incorporação". De fato, Rawls ao se pronunciar sobre psicologia moral agostiniana afirma:

\begin{abstract}
Ora, um traço essencial da psicologia moral agostiniana na Religião é que as falhas morais de todos os tipos, desde as falhas menores da fragilidade e da impureza aos piores extremos da malevolência e perversidade dos quais somos capazes devem todas surgir, não dos desejos da nossa natureza física e social, mas unicamente do exercício da nossa livre faculdade de escolha (Rel I 6:29-32 [23-27]. E por esse exercício nos mantemos plenamente responsáveis. (2000: 294/2005: 337).
\end{abstract}

E na sequência da citação acima, Rawls oferece como abono justamente a conhecida passagem da Religião em que Kant assevera:

\begin{abstract}
a liberdade do arbítrio tem a qualidade inteiramente peculiar de ele não poder ser determinado a uma ação por móbil algum a não ser apenas enquanto o homem o admitiu na sua máxima (in seine Máxime aufgenommen hat) (o transformou para si em regra universal de acordo com a qual se quer comportar); só assim é que um móbil seja ele qual for, pode subsistir juntamente com a absoluta espontaneidade do arbítrio (a liberdade) (RGV AA 06: 29-30).
\end{abstract}

Essa é precisamente a passagem da Religião que Allison usa em apoio à sua etiqueta "tese da incorporação". De acordo com Allison, na Religião encontramos a mais completa e mais importante explicação de Kant de sua concepção de espontaneidade prática (1990: 39). Allison afirma que tal pretensão de Kant, em Religião (Ak 23), pode ser nomeada de tese da incorporação (Incorporation Thesis). De acordo com tal tese fica 
agir. Uma inclinação pode se tornar uma razão para agir apenas com referência a uma regra ou princípio de ação, que dita que devemos perseguir a satisfação desta inclinação ou desejo. Além disso, [...] a própria adoção de tal regra não pode ser considerada como uma conseqüência causal do desejo ou, mais exatamente, de ser um estado desiderativo. Ao contrário, ela tem de ser concebida como um ato de espontaneidade por parte do agente (Allison, 1990: 40).

\section{Psicologia moral maniqueísta}

Segundo Rawls, "a ideia básica da psicologia moral maniqueísta consiste em que temos dois eus: um deles é o eu bom, que temos enquanto inteligências pertencentes ao mundo inteligível; o outro é o eu mau, que temos enquanto seres naturais pertencentes ao mundo sensível" (2000: 303/2004: 348). É preciso salientar que Rawls não afirma que Kant tenha sustentado a psicologia moral maniqueísta. Rawls sequer pensa que Kant teria assumido para si mesmo tal visão. Portanto, Rawls não se compromete nem com uma imputação textual da psicologia moral maniqueísta a Kant, nem como uma interpretação de que Kant poderia tê-la assumido para si mesmo. Na verdade, para Rawls, a doutrina explícita de Kant é a psicologia moral agostiniana (2000: 303/2004: 347).

Ao discutir o que denominarei a psicologia moral maniqueísta, não afirmo que Kant tenha em algum momento sustentado uma tal visão, ou mesmo que a tenha formulado claramente para si mesmo. Dou esse nome a sua tendência de dizer certas coisas e expressá-las de uma maneira e com um tom que, uma vez que nos concentramos nelas, surgem uma certa psicologia moral. A razão para discuti-la reside em que ela explicita um desenvolvimento do pensamento de Kant na Religião, ou ao menos uma articulação mais nítida de sua visão, já que ele se encarregou de considerar a religião com alguma minúcia. [...] A maneira e o tom da tendência maniqueísta estão frequentemente presentes, mas a doutrina explícita é a agostiniana (2000: 303/2004: 347).

Pode-se dizer, a partir dessa passagem, que, quando Kant teve de pensar articuladamente liberdade, moralidade e imputação, ele apresentou uma posição agostiniana. Com respeito a isso estou de acordo com Rawls. Acontece que algumas vezes Kant está apenas tentando elucidar o sentido de liberdade e o que ele diz a esse respeito compromete os juízos de imputação, seja obscurecendo o seu sentido, seja deixando esses juízos aparentemente embargados face à possível presença subjacente de uma psicologia moral maniqueísta.

E essa presença, ainda que apenas implícita, da psicologia moral maniqueísta produz evidentes dificuldades quando se toma em consideração a necessidade de explicar e justificar 
nossos juízos ordinários de imputabilidade moral. Com razão, Rawls assinala:

\begin{abstract}
Pois, como membros do mundo inteligível, devemos ver a todos nós como seres que não têm outra escolha senão agir segundo a lei moral (não temos senão essa predisposição), ao passo que, como membros do mundo natural, devemos ver a todos nós como seres que não tem outra escolha senão buscar a própria felicidade. Se percebêssemos a nós mesmos dessa maneira a partir do ponto de vista prático, pareceria impossível pensar a nós mesmos como igualmente responsáveis. (2000: 304-305/ 2004: 349)
\end{abstract}

De fato, assumir uma disjunção exaustiva do tipo ou causalidade natural=heteronomia ou liberdade=autonomia implica adotar uma concepção "demasiado esquemática e simplista". Desse modo, o que Kant revela parece ser uma assimilação da heteronomia da vontade com o arbitrium brutum tal como definido a partir da Crítica da razão pura (B 562 e B 830). Ora, isso é insustentável se Kant quer manter a idéia de que os seres humanos não são patologicamente necessitados, mas apenas patologicamente afetados. Embora a possibilidade de afecção por móbiles sensíveis seja uma condição necessária para se entender o arbítrio humano, ela não é uma condição suficiente.

Em outras palavras, a posição de Rawls acerca da psicologia moral maniqueísta poderia ser entendida assim: não há o que imputar se só é livre quem age moralmente. No domínio da liberdade só existiriam ações dignas de louvor. No domínio da natureza, encontrar-se-iam ações reprováveis, mas não se poderia legitimamente censurar os agentes, uma vez que esses não seriam livres. Por certo, Kant julgaria tal compreensão insustentável. Contudo, a questão aqui diz respeito ao seu texto - esse me parece ser o ponto de Rawls, isto é, à carência de esclarecimento sobre com qual psicologia moral Kant estaria realmente comprometido.

Acredito que Rawls está certo em interpretar que a Religião representa um desenvolvimento do pensamento moral de Kant (cf. 2000: 303/2005: 347). De fato, na Religião Kant admite expressamente a possibilidade de uma decisão inteligível pelo mal. Com a doutrina do "mal radical" (radikales Böse), se afirma claramente que o homem que se afasta da lei moral, adotando como princípio de sua máxima o amor próprio, é livre (RGV AA 06: 29, 31, 36). Assim, é lícito pensar que a clara admissão da possibilidade de uma decisão inteligível pelo mal sugere ter Kant reconhecido certa insuficiência quanto ao tratamento desta questão nas obras anteriores, especialmente Fundamentação e Crítica da razão prática. Para Valério Rohden, por meio da interconexão entre necessidade prática e liberdade "Kant não pode pensar a liberdade para o mal. Esta liberdade para o mal é pensada no livro sobre a Religião como fundada num ethic@-Florianópolis v. 12, n. 1, p. 101 -111, Jun. 2013. 
mundo 'inteligível' indeterminável"' (1981: 143).

Se confrontarmos a recusa de Kant, na Religião, da sensibilidade como fundamento do mal, com os $\S \S 2$ e 14 da III seção da Fundamentação (GMS AA 04: 446-447 e GMS AA 04: 452), poderemos perceber uma diferença significativa. Na Fundamentação Ak 446-447 e Ak 452 Kant compreende a heteronomia da vontade dentro da legalidade natural. Em Ak 446 se lê que "a necessidade natural era uma heteronomia das causas eficientes" (GMS AA 04: 446) e em Ak 452 Kant entende a heteronomia como se ela significasse a submissão de todas as ações do homem como ser sensível às leis naturais (cf. GMS AA 04: 452). Ora, se se aceita que ou a causalidade é natural ou é causalidade segundo leis morais (imutáveis), só sendo possível, portanto, necessidade natural ou autonomia, sucumbe-se ao problema da imputabilidade. Com efeito, desde que na natureza tudo ocorre, incluindo aí, obviamente, as ações humanas, segundo uma conexão causal em que um efeito "Y" é resultado necessário de uma causa "X", a qual por sua vez depende de outra causa, não se pode tomar tal modelo de causalidade como base para a imputação moral. O problema é que aí os eventos não são iniciados espontaneamente, mas são necessários desdobramentos, em última instância, físicos. Logo, inexistindo a possibilidade de se conceber um agente atuando livremente, a natureza não pode servir como recurso a quem se interessa pela responsabilidade moral. Restam, assim, os processos causais por liberdade. Mas, tendo em vista o modo como Kant parece entender a liberdade no $\$ 2$ da III seção da Fundamentação (cf. GMS AA 04: 446-447), aí também não se pode imputar. De fato, ao pretender esclarecer o conceito positivo de liberdade, Kant, no início da III seção, sustenta que se "a vontade é, em todas as ações, uma lei para si mesma" (GMS AA 04: 446) então a vontade é livre. Logo, uma vontade livre é uma vontade autônoma. Isso quer dizer que ela, sendo lei para si mesma, não adota senão uma máxima que pode "ter-se a si mesma por objeto como lei universal. Isto, porém, é precisamente a fórmula do imperativo categórico e o princípio da moralidade; assim pois, vontade livre e vontade submetida a leis morais são uma e a mesma coisa." (GMS AA 04: 446-447).

Sendo assim, Kant se expõe facilmente a seguinte crítica: se uma vontade livre implicar necessariamente o cumprimento da lei moral, alguém que não segue a lei moral possuirá uma vontade não livre e, assim, não poderá ser lhe imputada a responsabilidade por uma ação contrária à moralidade. Quer dizer, uma vez que se identifique liberdade e moralidade, parece ser necessário admitir, como afirma Ferdinand Alquié, que "nós não somos mais livres desde que nós 
não somos mais morais e que nós não somos mais responsáveis por nossas faltas" (s/d: 96).

\section{Mal moral e a tese dos dois mundos}

Em suas Lectures on the History of Moral Philosophy, Rawls dá a impressão de abandonar a distinção entre mundo sensível e mundo inteligível.

\footnotetext{
Não há mais [AP: com a psicologia moral agostiniana] um dualismo entre um eu bom e um eu mau - dois eus, cada um dotado de uma única predisposição, e ambas as predisposições propensas a chocar-se uma com a outra -, mas um único eu com três predisposições, sendo todas elas disposições para o bem. (2000: 305/ 2005: 350)
}

Rawls está se referindo à sua ideia de que um dos eus assumido pela psicologia moral maniqueísta é constituído pelas predisposições à animalidade e humanidade, as quais podem ser reduzidas ou consideradas "paralelas" à predisposição ao amor de si mesmo (cf. 2000: 304 /2005: 348). Já o outro eu, o eu bom, é dotado apenas da predisposição (predisposition) à personalidade (cf. 2000: 304 /2005: 348). Quer dizer, Rawls interpreta a psicologia moral maniqueísta, potencialmente presente na Fundamentação, com recursos conceituais da primeira parte da Religião. Até aí, não vejo razões substantivas para discordar de Rawls.

O que, a meu ver, é um erro de Rawls é a sugestão de abandono da distinção entre mundo sensível e mundo inteligível, uma vez assumida a psicologia moral agostiniana. Acredito que a psicologia moral agostiniana pode até envolver uma melhor qualificação do alcance moral da distinção entre os mundos sensível e o inteligível, mas não o seu simples abandono. Colocada de modo irrestrito e não qualificada é improcedente a afirmativa de que a psicologia moral agostiniana abandonaria o dualismo entre os eus. Certamente não cabe mais flertar com um dualismo maniqueísta, mas permanece um dualismo, o dualismo entre eu natural e eu livre, o dualismo entre mundo sensível e inteligível, crucial para se entender o mal radical.

No meu entender, Rawls deveria ter deixado claro que a teoria dos dois mundos, não obstante tenha sido evocada por ele a partir da III seção da Fundamentação a fim de criticar a psicologia moral maniqueísta, pode ser interpretada não como base para oposição entre eu mau natural e eu bom moral, mas como uma base metafísica para entendermos o contraste entre um eu natural e um eu livre, isto é, entre um eu submetido à leis naturais, nem bom nem mau, e um eu sob a lei moral, podendo ser bom ou mau à medida que seu arbítrio escolhe inteligivelmente 
acolher ou não a lei moral como móbil da ação. A distinção permanece, pois ela é crucial justamente para sustentar a psicologia moral agostiniana. Essa omissão ou descuido me parece uma grave deficiência na leitura do mal radical empreendida por Rawls.

\section{Já na Fundamentação é possível encontrar recursos conceituais que permitem constatar a presença da psicologia moral agostiniana}

Rawls não faz a tentativa de utilizar recursos conceituais internos à Fundamentação a fim de pensar uma possível psicologia moral agostiniana na obra de 1785. Contudo, como já observado, Rawls não está comprometido com a tese forte de que há uma clara ausência da psicologia moral agostiniana da Fundamnetação. Assim, o meu ponto, aqui, será apenas desenvolver brevemente algo ausente na análise de Rawls. Basicamente duas passagens da Fundamentação podem ser convocadas para se defender a ideia de uma psicologia moral agostiniana. Tenho em mente Fundamentação II, §12 (GMS AA 04: 412-413) e Fundamentação II $\S 80$ (GMS AA 04: 441).

No início do $\S 12$ da II seção da Fundamentação, em que Kant faz uma espécie de introdução aos imperativos, se lê a conhecida passagem:

\footnotetext{
Tudo na natureza age segundo leis. Só um ser racional tem a capacidade de agir segundo a representação das leis, isto é, segundo princípios, ou: só ele tem uma vontade. Como para derivar as ações das leis é necessária a razão, a vontade não é outra coisa senão razão prática (GMS AA 04: 412-413).
}

Essa passagem mostra, em primeiro lugar, a posição sempre clara de Kant acerca da legalidade da natureza, isto é, de que todo fenômeno está submetido à necessidade das leis da natureza. Na natureza tudo ocorre segundo uma regularidade estritamente determinada. Mas este trecho mostra também - e é isso naturalmente o que mais interessa aqui - que, não obstante a determinação necessária do que ocorre na natureza, a peculiaridade de um ser racional permitenos ir além do necessitarismo do nach Gesetzen (segundo leis). É possível conceber um "agir segundo a representação das leis" (nach der Vorstellung der Gesetze), o que significa pensar em uma capacidade de agir segundo princípios (nach Prinzipen). Concebido isso, pode-se nomear tal capacidade de vontade (Wille), atribuindo-a exclusivamente a um ser racional.

Assumo aqui a interpretação segundo a qual "representação das leis" não significa 
representação exclusiva de leis morais. Essa posição é convergente com o pensamento de Allison e Paton a esse respeito. Paton afirma que "de fato Kant define uma vontade como um poder para determinar a si mesma a agir de acordo com a concepção de certas leis - isto é, de acordo com máximas" (1970: 82). Allison, por sua vez, considera que "agir de acordo com a representação de leis deve ser entendido como equivalente a agir com base em máximas" (1990: 86).

A fim de deixar mais claro o que tenho em mente aqui, vale à pena fazer algumas observações sobre a noção de heteronomia. Em Fundamentação II seção §80 (GMS AA 04: 441), a heteronomia significa uma vontade cuja lei não é por si mesma dada, mas sim é dada pelo objeto por meio de sua relação com a vontade. Segundo Kant, esta "relação, quer assente na inclinação, quer em representações da razão, só pode tornar possíveis imperativos hipotéticos". Aqui interessa reter que uma vontade heterônoma segue uma lei dada por um objeto mediante a relação entre esse e a vontade, relação baseada ou na inclinação ou em representações da razão. Ora, uma inclinação (Neigung) é "dependência em que a faculdade de desejar está em face das sensações" (GMS AA 04: 441, n.). Esta dependência (Abhängigkeit) não pode querer dizer que a faculdade de desejar seja patologicamente necessitada. É melhor compreender essa dependência no sentido em que Kant fala, na mesma passagem citada, de uma vontade dependente (abhängigen Willen), a qual tem o significado de uma vontade "que não é por si mesma em todo o tempo conforme à razão", diferentemente de uma vontade divina. Desse modo, pode-se conceber a relação entre vontade e inclinação sem retirarmos a espontaneidade da primeira. Se isso é razoável com respeito ao conceito de inclinação, muito mais tranquila é a situação da noção de "representação da razão". É suficiente, neste caso, reportar-se ao que foi dito atrás sobre o $§ 12$ da II seção. Dessa forma, a heteronomia da vontade também comporta liberdade. Decerto tal conclusão colide com o início da III seção da Fundamentação. Porém julgo-a mais consistente, tendo em vista as dificuldades que a tese da sinonímia apresenta.

Acredito ter conseguido mostrar, ao longo desse texto, a pertinência, em linhas gerais, da leitura de Rawls acerca da psicologia moral em Kant suas linhas mais gerais. Minha divergência resultou mais local que global. Tentei indicar que não é merecedora de acolhimento a possível inoperância, ou abandono da distinção entre mundo sensível e mundo inteligível na Religião. Rawls também poderia ter se servido de elementos conceituais endógenos à Fundamentação para destacar a presença latente, nessa obra, da psicologia moral agostiniana. 


\section{Bibliografia}

AGOSTINHO. O Livre Arbitrio. Tradução, organização, introdução e notas de Nair de Assis Oliveira. São Paulo: Paulus, 1995.

. A Cidade de Deus (contra os pagãos). I parte. $4^{\mathrm{a}}$ edição. Tradução de Oscar Paes Leme. Petrópolis: Vozes, 1999.

. A Cidade de Deus (contra os pagãos). II parte. $3^{\text {a }}$ edição. Tradução de Oscar Paes Leme. Petrópolis: Vozes, 1999.

ALLISON, Henry. Kant's Theory of Freedom. New York: Cambridge University Press, 1990.

.Reflections on the banality of (radical) evil: a kantian analysis". In: Idealism and freedom: Essays on Kant's theoretical and practical philosophy. New York: Cambridge University Press, 1996.

ALQUIÉ, Ferdinand (s/d): La morale de Kant. Centre de Documentations Universitaire, Place de la Sorbonne Paris V.

. Leçons sur Kant. La morale de Kant. Table Ronde: Paris, 2005.

FACKENHEIM, Emil. "Kant and Radical Evil". In: CHADWICK, Ruth F. (ed.). Immanuel Kant: Critical Assessments. Vol. III: Kant's Moral and Political Philosophy. London e New York: Routledge, 1995. (reimpressão), p. 259-273. [1a. edição 1992].(publicado originalmente em University of Toronto Quartely 23 (1954) 339-53).

HUDSON, Hud (1991): "Whille, Willkür, and the Imputability of Immoral Actions" Kant Studien, 82 (2), p. 179-196.

KANT, Immanuel. Crítica da Razão Pura. $3^{\text {a }}$ ed. Tradução Manuela Pinto dos Santos e Alexandre Fradique Morujão. Lisboa: Fundação Calouste Gulbenkian, 1994.

. Crítica da Razão Prática. Tradução com introdução e notas de Valério Rohden. São Paulo: Martins Fontes, 2002.

. Fundamentação da Metafísica dos Costumes. Tradução de Paulo Quintela. São Paulo: Abril Cultural, 1980.

1992.

. A Religião nos limites da simples razão. Tradução de Artur Morão. Lisboa: Ed. 70,

. Die Religion innerhalb der Grenzen der blossen Vernunft. Werkausgabe VIII. Ed. W. Weischedel. Frankfurt: Surkamp, 1991.

Grundlegung zur Metaphysik der Sitten. Werkausgabe VII. Ed. W. Weischedel. Frankfurt: Surkamp, 1991.

ethic@-Florianópolis v. 12, n. 1, p. 101 -111, Jun. 2013. 
$\overline{\text { Surkamp, }} 1991$.

Kritik der praktischen Vernunft. Werkausgabe VII. Ed. W. Weischedel. Frankfurt: 1991. . Die Metaphysik der Sitten. Werkausgabe VIII. Ed. W. Weischedel. Frankfurt, Surkamp, . A Metafisica dos Costumes. Tradução de José Lamego. Lisboa: Gulbenkian, 2005.

PATON, H. J. The Categorical Imperative: A Study in Kant's Moral Philosophy. London: Hutchinson, 1970.

RAWLS, John. História da filosofia moral. Tradução de Ana Aguiar Cotrim. São Paulo: Martins Fontes, 2005.

. Lectures on the History of Moral Philosophy. Org. de Barbara Herman. Cambridge (EUA), Londres: Harvard University Press, 2000.

ROHDEN, Valério. Interesse da Razão e Liberdade. São Paulo: Ática, 1981.

ROHS, Peter. "Teoria Transcendental-filosófica da ação - um esboço". In: ROHDEN, Valério. (org). Racionalidade e Ação. Porto Alegre: UFRGS e Instituto Goethe, 1992, p. 9-24.

SILBER, John. "The ethical significance of Kant's religion". In: KANT, I. Religion Within the Limits of Reason Alone. Ed. T. M. Greene and H. H. Hudson. New York: Harper and Row, 1960, p. lxxix-cxxxiv.

WALKER, Ralph. Kant: The arguments of the Philosophers. London, Routledge and Kegal Paul, 1982. . “Kant tem uma filosofia moral?”. Filosofia Politica, 5, 7-22. 1989.

1999. . Kant: Kant e a lei moral. Tradução de Oswaldo Giacóia Junior. São Paulo: Ed. Unesp, 